Fenótipo cintura hipertrigliceridêmica:

\section{fatores associados e comparação com outros indicadores de risco cardiovascular e metabólico no ELSA-Brasil}

\author{
Hypertriglyceridemic waist phenotype: associated \\ factors and comparison with other cardiovascular \\ and metabolic risk indicators in the ELSA-Brasil \\ study
}

\section{Fenotipo cintura hipertrigliceridémica: factores asociados y comparación con otros indicadores de riesgo cardiovascular y metabólico en el ELSA-Brasil}

Roberta Souza Freitas 1

Maria de Jesus Mendes da Fonseca 2

Maria Inês Schmidt 3

Maria del Carmen Bisi Molina 4

Maria da Conceição Chagas de Almeida 5

doi: 10.1590/0102-311X00067617

\title{
Resumo
}

O objetivo deste estudo foi estimar a prevalência do fenótipo cintura hipertrigliceridêmica $(F C H)$ em participantes do Estudo Longitudinal da Saúde do Adulto (ELSA-Brasil), identificar fatores de risco associados e comparar com outros indicadores de risco cardiovascular e metabólico. Trata-se de um estudo transversal com dados da linha de base de uma coorte de servidores públicos. O FCH é definido pela presença simultânea de circunferência da cintura (CC) aumentada ( $\geq 80 \mathrm{~cm}$ para mulheres, $\geq 90 \mathrm{~cm}$ para homens de acordo com a Federação Internacional de Diabetes - IDF; e $\geq 88 \mathrm{~cm}$ para mulheres, $\geq 102 \mathrm{~cm}$ para homens de acordo com o Programa Nacional de Educação sobre o Colesterol dos Estados Unidos - NCEP) e hipertrigliceridemia. A associação entre as variáveis independentes e FCH foi testada por meio de modelos de regressão logística multivariada. O FCH foi comparado também com outros indicadores de risco cardiovascular e metabólico por meio de testes de correlação, indice kappa, sensibilidade e especificidade. Após exclusões, foram analisados 12.811 participantes. A prevalência do FCH variou de 24,7\% (IDF) a 13,3\% (NCEP). FCH foi associado a ter idade mais avançada, ao consumo excessivo de álcool, ser ex-fumante, apresentar HDL baixo, não-HDL alto e PCR aumentado, independente do sexo ou critério de definição. FCH associou-se a indicadores de risco cardiovascular, especialmente à síndrome metabólica. A elevada prevalência de FCH e sua associação com indicadores de risco cardiovascular, especialmente com a síndrome metabólica, apoia sua utilização como ferramenta de triagem de risco cardiometabólico na prática clinica.

\section{Correspondência}

R. S. Freitas

Instituto de Saúde Coletiva, Universidade Federal da Bahia. Rua Basílio da Gama s/n, Salvador, BA 40110-040, Brasil. beta_freitas_@hotmail.com

\footnotetext{
1 Instituto de Saúde Coletiva, Universidade Federal da Bahia, Salvador, Brasil.

2 Escola Nacional de Saúde Pública Sergio Arouca, Fundação Oswaldo Cruz, Rio de Janeiro, Brasil.

3 Faculdade de Medicina, Universidade Federal do Rio Grande do Sul, Porto Alegre, Brasil.

4 Universidade Federal do Espírito Santo, Vitória, Brasil.

5 Instituto Gonçalo Moniz, Fundação Oswaldo Cruz, Salvador, Brasil.
} 


\section{Introdução}

A principal causa de mortalidade entre adultos no mundo ${ }^{1}$ e em todas as regiões brasileiras (Departamento de Informática do SUS. http://tabnet.datasus.gov.br/cgi/idb2010/matriz.htm\#mort, acessado em 02/Dez/2015) são as doenças cardiovasculares (DCV). A redução da mortalidade por essas doenças envolve prevenção e controle dos seus fatores de risco. Assim, o conhecimento acerca desses fatores e dos indicadores de risco cardiovascular e metabólico pode assegurar um melhor embasamento e planejamento de políticas públicas.

Um dos indicadores propostos para identificar o risco cardiovascular foi o fenótipo cintura hipertrigliceridêmica (FCH), sugerido por Lemieux et al. 2. Ele envolve a mensuração de medidas simples, de baixo custo e facilmente aplicáveis à clínica e à saúde pública, como a circunferência da cintura (CC) e o triglicérides (TG), que devem estar aumentados simultaneamente. Demonstrou-se que o FCH é um bom indicador de risco cardiovascular e metabólico, podendo predizer esse risco mais precocemente que outros, como por exemplo, a síndrome metabólica (SM) 3,4.

Estudos brasileiros e de outros países identificaram que o FCH está associado a fatores de risco cardiovascular e metabólico, como obesidade, alterações dislipidêmicas, pressão arterial elevada, tabagismo, proteína C reativa (PCR) e tecido adiposo visceral aumentado 4,5,6,7,8, entretanto foram realizados com amostras reduzidas e específicas da população, não abrangendo sua diversidade. Nesse sentido, avaliar diferentes grupos etários, sexo e regiões é necessário para abranger a população brasileira de maneira mais ampla. Estudos com esse intuito podem garantir um melhor planejamento de políticas públicas voltadas à prevenção de DCV e metabólicas e para consolidação e utilização do FCH na saúde pública.

O presente estudo tem por objetivos estimar a prevalência do FCH e identificar seus fatores associados entre homens e mulheres no Estudo Longitudinal de Saúde do Adulto (ELSA-Brasil) e compará-lo a outros indicadores de risco cardiovascular e metabólico (escore de Framingham, SM e índice HOMA).

\section{Métodos}

Este estudo é um corte transversal da linha de base da coorte do ELSA-Brasil, realizado no período correspondente a 2008-2010. O ELSA-Brasil é um estudo multicêntrico composto por 15.105 servidores públicos, ativos e aposentados, com idade entre 35 e 74 anos, de ambos os sexos, de seis instituições de ensino superior localizadas em cidades de diferentes regiões do Brasil (São Paulo, Belo Horizonte, Porto Alegre, Salvador, Rio de Janeiro e Vitória).

O ELSA-Brasil tem o objetivo de investigar a incidência e progressão de doenças crônicas não transmissíveis (DCNT) e incluiu informações sociodemográficas, história clínica, exposição ocupacional, história familiar de doenças, o acesso aos serviços de saúde, estilo de vida, saúde mental, além de medidas antropométricas e laboratoriais ${ }^{9}$. Foi submetido e aprovado pela Comissão Nacional de Ética em Pesquisa e por todos os Comitês de Ética das seis instituições envolvidas. Todos os participantes assinaram termo de consentimento livre e esclarecido e foram garantidos a eles todos os direitos éticos 9,10. Toda a equipe de pesquisa passou por um rigoroso controle de qualidade para garantir a padronização do estudo 10 .

Para este artigo, foram excluídos os participantes que fizeram uso de medicamentos para a redução dos níveis de TG (fibratos, niacinas e estatinas), aqueles com TG acima de $800 \mathrm{mg} / \mathrm{dL}$, por se tratar de dislipidemia grave 11, com índice de massa corporal (IMC) $>40 \mathrm{~kg} / \mathrm{m}^{2}$ e que realizaram cirurgia bariátrica. Assim, 15.093 participantes tiveram a CC e a concentração de TG mensurados; desses, 2.282 foram excluídos pelos critérios citados. 


\section{Variáveis e análise dos dados}

\section{- Fenótipo cintura hipertrigliceridêmica}

O FCH, variável dependente do estudo, é de um indicador composto pelas medidas de CC e do TG. Essas medidas foram categorizadas de acordo com pontos de corte que indicam risco de desenvolvimento de complicações cardiovasculares e metabólicas.

A CC foi medida no ponto médio entre a borda inferior do arco costal e a crista ilíaca na linha axilar média, com trena antropométrica de $200 \mathrm{~cm}$ (Cescorf Equipamentos para Esporte Ltda., Porto Alegre, Brasil) 12. Neste estudo, utilizaram-se dois pontos de corte para definir essa variável em decorrência da falta de consenso na literatura. A CC baseada na Federação Internacional de Diabetes (IDF) 12 foi classificada em adequada $<80 \mathrm{~cm}$ para mulheres; $<90 \mathrm{~cm}$ para homens e inadequada $\geq 80 \mathrm{~cm}$ para mulheres; $\geq 90 \mathrm{~cm}$ para homens, enquanto a baseada no Programa Nacional de Educação sobre o Colesterol dos Estados Unidos (NCEP) 13,14 foi classificada, por sua vez, em adequada $<88 \mathrm{~cm}$ para mulheres; $<102 \mathrm{~cm}$ para homens e inadequada $\geq 88 \mathrm{~cm}$ para mulheres; $\geq 102 \mathrm{~cm}$ para homens.

Os TG foram mensurados por meio do ensaio colorimétrico enzimático - peroxidase de fosfato de glicerol (ADVIA Chemistry; Siemens Healthcare Diagnósticos Ltda., São Paulo, Brasil) 11. Para ambas as medidas de CC, utilizou-se o mesmo ponto de corte para TG, definido como adequado $<150 \mathrm{mg} / \mathrm{dL}$ e inadequado $\geq 150 \mathrm{mg} / \mathrm{dL}$.

Os indivíduos que apresentaram as duas medidas aumentadas concomitantemente foram classificados no grupo com o FCH, e os demais foram incluídos no grupo sem esse fenótipo. O FCH baseado nos pontos de corte de CC de acordo com a IDF foi denominado FCH-IDF, e o de acordo com a NCEP, FCH-NCEP.

\section{- Variáveis sociodemográficas}

Os indivíduos foram classificados de acordo com sexo (masculino e feminino), grupo etário (35-44 anos, 45-54 anos, 55-64 anos e 65-74 anos), nível de escolaridade (Superior completo, Médio completo, Fundamental completo e até Fundamental incompleto), cor/raça autorreferida (preta, parda, branca, amarela e indígena), situação conjugal (casado(a)/com companheiro(a), separado(a)/divorciado(a), solteiro(a) e viúvo(a)) e cobertura do seguro saúde privado (sim e não).

\section{- Variáveis comportamentais}

A atividade física foi avaliada para o domínio tempo livre por meio do Questionário Internacional de Atividade Física (IPAQ) versão longa, validado para o Brasil 15, e relatada em minutos/semana. Indivíduos foram classificados em ativos (quando realizavam atividade física vigorosa por tempo maior ou igual a 75 minutos/semana ou atividade física moderada, caminhada ou a soma de todas elas por 150 minutos/semana ou mais) e inativos (atividade vigorosa por menos de 75 minutos/semana ou outras atividades menos intensas por menos de 150 minutos/semana) 16.

O consumo excessivo de álcool foi categorizado como sim (homens $\geq 210 \mathrm{~g}$ álcool/semana; mulheres $\geq 140 \mathrm{~g}$ álcool/semana) e não (homens < 210g álcool/semana; mulheres < 140g álcool/semana) 17.

Quanto ao tabagismo, os indivíduos foram classificados em fumante (aquele que já fumou 100 cigarros ao longo da vida e continua fumando), ex-fumante (aquele que já fumou 100 cigarros ao longo da vida, mas atualmente parou de fumar) e não fumante (aquele que fumou menos de 100 cigarros ao longo da vida) 18 .

\section{- Variáveis de saúde}

Foram considerados hipertensão arterial valores da pressão arterial sistólica (PAS) $\geq 140 \mathrm{mmHg}$, pressão arterial diastólica (PAD) $\geq 90 \mathrm{mmHg}$, ou o uso de medicamento anti-hipertensivo. O diabetes foi definido tanto por meio do autorrelato de diabetes ou tratamento com insulina ou hipoglicemiante, quanto por valores laboratoriais de glicemia de jejum $\geq 126 \mathrm{mg} / \mathrm{dL}$, ou glicose $\geq 200 \mathrm{mg} / \mathrm{dL}$ após o teste de tolerância ou hemoglobina glicada (A1c) $\geq 6,5 \%$. Identificou-se a presença de DCV por meio 
do autorrelato de pelo menos uma das seguintes doenças: infarto do miocárdio, revascularização, acidente vascular encefálico e insuficiência cardíaca.

A doença renal crônica foi definida por uma estimativa da taxa de filtração glomerular (TFG) por meio da equação CKD-EPI (Chronic Kidney Disease Epidemiology Collaboration) ${ }^{19}$, sem correção para raça 20 . Os participantes foram classificados com presença de doença renal (TFG $<60 \mathrm{~mL} /$ $\left.\mathrm{min} / 1,73 \mathrm{~m}^{2}\right)$ ou ausência $\left(\mathrm{TFG} \geq 60 \mathrm{~mL} / \mathrm{min} / 1,73 \mathrm{~m}^{2}\right) 21$.

A variável autopercepção de saúde foi categorizada em boa, regular, ruim. O IMC foi classificado em baixo peso (IMC $\left.<18,5 \mathrm{~kg} / \mathrm{m}^{2}\right)$, peso normal $\left(18,5 \leq \mathrm{IMC}<25,0 \mathrm{~kg} / \mathrm{m}^{2}\right)$, sobrepeso $(25,0 \leq \mathrm{IMC}<$ $30 \mathrm{~kg} / \mathrm{m}^{2}$ ), obesidade (IMC $\geq 30 \mathrm{~kg} / \mathrm{m}^{2}$ ).

O colesterol não-HDL (lipoproteínas de não-alta-densidade) foi classificado em desejável (< $160 \mathrm{mg} / \mathrm{dL}$ ) e alto ( $\geq 160 \mathrm{mg} / \mathrm{dL}) 11$ e o HDL (lipoproteína de alta densidade) em desejável ( $>60 \mathrm{mg} /$ $\mathrm{dL})$; limítrofe $(40-60 \mathrm{mg} / \mathrm{dL})$; baixo $(<40 \mathrm{mg} / \mathrm{dL}) 11$. A PCR foi classificada em normal $(<3 \mathrm{mg} / \mathrm{L}) \mathrm{e}$ aumentada $(\geq 3 \mathrm{mg} / \mathrm{L}) 22$. Os participantes foram classificados sem ou com uma, duas ou mais histórias de doenças cardiovasculares e metabólicas (infarto do miocárdio, acidente vascular cerebral, hipertensão, diabetes, revascularização ou outra doença do coração) entre os membros da família (pai, mãe ou irmão).

As mulheres ainda foram classificadas em não menopausadas, menopausa natural, cirúrgica ou outros.

\section{- Indicadores de risco cardiovascular e metabólico}

O escore de Framingham foi composto pelas variáveis idade, IMC, pressão arterial sistólica ou uso de medicação anti-hipertensiva, tabagismo atual e status de diabetes 23 . Os participantes foram classificados em grupos quanto ao risco de DCV em 10 anos como baixo risco $(\leq 20 \%$ de probabilidade de apresentar um evento cardiovascular) e alto risco (>20\%) 24 .

A presença de resistência à insulina foi verificada por meio do modelo de avaliação da homeostase da resistência à insulina (HOMA-IR) 25. Os valores acima do percentil 75 foram considerados indicativos de presença de resistência à insulina 26,27,28, correspondendo a um ponto de corte $\geq 3$. Os indivíduos foram classificados em não resistente à insulina $(<3)$ e resistente à insulina $(\geq 3)$.

A SM foi composta pelas variáveis obesidade abdominal (avaliada pela CC de acordo com IDF e NCEP), hipertrigliceridemia (TG $\geq 150 \mathrm{mg} / \mathrm{dL}$ ou tratamento específico para essa anormalidade lipídica), baixo colesterol HDL (HDL $<50 \mathrm{mg} / \mathrm{dL}$ para mulheres ou $<40 \mathrm{mg} / \mathrm{dL}$ para homens, ou tratamento específico), hipertensão arterial (PAS $\geq 130 \mathrm{mmHg}$ ou PAD $\geq 85 \mathrm{mmHg}$ ou tratamento da hipertensão previamente diagnosticada) e hiperglicemia em jejum (glicose $\geq 100 \mathrm{mg} / \mathrm{dL}$ ou diabetes tipo 2 diagnosticado previamente). O FCH-IDF foi comparado com SM estabelecida pela IDF que tem como critério obrigatório a presença de obesidade abdominal e mais duas variáveis 12 . O FCH-NCEP foi comparado com a SM segundo critérios do NCEP-ATPIII (Adult Treatment Panel III) que define três ou mais variáveis para presença de SM 14 .

Considerando as diferenças comportamentais e biológicas existentes entre homens e mulheres, toda a análise de dados foi estratificada por sexo. Devido à falta de consenso na literatura em relação ao ponto de corte mais adequado da CC para a população brasileira, optou-se também por trabalhar com dois indicadores de cintura hipertrigliceridêmica realizando a análise para cada um deles. As características da população foram descritas mediante o cálculo das frequências e suas diferenças em relação à FCH foram comparadas por meio do teste qui-quadrado de Pearson ao nível de 5\%.

Foram selecionadas para os modelos as variáveis sociodemográficas, comportamentais e de saúde associadas à cintura hipertrigliceridêmica na etapa bivariada $(\mathrm{p} \leq 0,05)$ e aquelas que na avaliação simultânea de colinearidade apresentaram coeficiente de correlação rho < 0,60 (matriz tetracórica). Questões teóricas também foram levadas em conta para a seleção das variáveis para o modelo.

A associação entre as variáveis independentes e FCH (variável dependente) foi testada por modelos de regressão logística multivariada. Algumas variáveis foram dicotomizadas nessa etapa. Foram criados quatro modelos de regressão relativos ao FCH-IDF e FCH-NCEP, segundo o sexo, com base em um modelo completo. Como medida de associação foram calculadas as odds ratio (OR), com os seus respectivos intervalos de 95\% de confiança (IC95\%). O diagnóstico do modelo deu-se por intermédio dos testes de qualidade de ajuste, utilizando os testes lfit e área sob a curva ROC. 
Considerando a SM, o escore de Framingham e o índice HOMA-IR como variáveis de referência em comparação ao $\mathrm{FCH}$, foram calculados sensibilidade, especificidade, índice kappa e correlação por meio da análise tetracórica. Os dados foram analisados pelo software estatístico Stata, versão 13 (StataCorp LP, Collage Station, Estados Unidos).

\section{Resultados}

Após exclusões, foram analisados 12.811 participantes, sendo 54,2\% (IC95\%: 53,3-55,0) do sexo feminino. A média de idade foi $51,1(\mathrm{DP}=8,8)$ anos. A maioria referiu nível superior completo $(52,1 \%$; IC95\%: 51,2-52,9), autodeclarou-se com cor/raça branca (51\%; IC95\%: 50,1-51,9) e avaliou seu estado de saúde como bom (82\%; IC95\%: 81,3-82,6). A proporção de indivíduos da Região Sudeste foi de $73,1 \%$, seguido da Região Nordeste com $13,7 \%$ e da Sul com $13,2 \%$. A prevalência de hipertrigliceridemia foi de 29,9\% (IC95\%: 29,1-30,7) e de sobrepeso e obesidade de acordo com IMC foram, respectivamente, de 40,1\% (IC95\%: 39,2-40,9) e 20,5\% (IC95\%: 19,8-21,2). A CC aumentada foi verificada em 64\% (IC95\%: 62,8-65,2) dos homens (CC $\geq 90 \mathrm{~cm}$ ) e 68,8\% (IC95\%: 67,7-69,8) das mulheres (CC $\geq$ 80cm). A prevalência global do FCH-IDF foi de 24,7\% (IC95\%: 24,0-25,5) e a do FCH-NCEP de 13,3\% (IC95\%: 12,7-13,8). Para a medida de FCH segundo a IDF, os valores foram distintos para homens e mulheres (31,6\% e 19\%, respectivamente). Por outro lado, quando se utilizou a medida de FCH de acordo com o estabelecido pelo NCEP, cerca de 13\% dos participantes de ambos os sexos apresentaram o fenótipo (dados não apresentados em tabelas).

Encontrou-se a maior proporção de $\mathrm{FCH}$ entre as mulheres de 65 a 74 anos, com menor nível de escolaridade, viúvas ou separadas/divorciadas e sem cobertura do seguro de saúde privado, segundo as duas classificações. Quanto aos homens, destacaram-se os de 55 a 64 anos, casados ou divorciados para o FCH-IDF, assim como ser branco ou indígena e ter cobertura do seguro de saúde privado para FCH-NCEP. Os participantes inativos, que consumiam álcool excessivamente e eram ex-fumantes ou fumantes apresentaram uma maior proporção de FCH em ambos os sexos e definições (Tabela 1).

Nas duas classificações e para ambos os sexos, foram encontrados maiores percentuais de FCH em todas as doenças e marcadores metabólicos inadequados. E também, para aqueles com percepção ruim do estado de saúde e entre mulheres menopausadas (especialmente as de causa cirúrgica). O mesmo padrão foi verificado para indicadores de DCV e metabólicas positivos (escore de Framingham, índice HOMA-IR e SM) (Tabela 2).

$\mathrm{Na}$ análise bruta, os fatores que apresentaram maior associação com FCH foram HDL baixo, não-HDL aumentado e PCR aumentado (Tabelas 3 e 4). No modelo ajustado, independentemente de classificação ou sexo, permaneceram associados ao $\mathrm{FCH}$ grupos etários mais velhos, consumo excessivo de álcool, tabagismo, autopercepção do estado de saúde negativa, HDL baixo, não-HDL alto e PCR aumentado. Além desses fatores, entre as mulheres, FCH foi associado à escolaridade inferior, FCH-IDF à situação conjugal separada/viúva ( $\mathrm{OR}=1,34$; IC95\%: 1,06-1,70) e casada/com companheiro (OR = 1,29; IC95\%: 1,03-1,61), e FCH-NCEP a uma ou mais história familiar de doenças (OR = 1,39; IC95\%: 1,01-1,91) (Tabela 3). Entre os homens, encontrou-se associação do FCH com prática de atividade física no tempo livre (FCH-IDF: OR = 1,27; IC95\%: 1,12-1,44; FCH-NCEP: OR = 1,41; IC95\%: 1,19-1,68), do FCH-IDF com história familiar de doenças (OR = 1,26; IC95\%: 1,06-1,51) e do FCH-NCEP com cor-raça branca ( $\mathrm{OR}=1,47$; IC95\%: 1,13-1,91) e não ter seguro de saúde privado $(\mathrm{OR}=1,35$; IC95\%: 1,13-1,61) (Tabela 4).

Entre os indicadores de risco cardiovascular e metabólico avaliados, o FCH apresentou melhor correlação com SM, com coeficientes maiores que 0,80 (correlação forte), independentemente do sexo ou da definição de FCH. A concordância entre o indicador supracitado e o FCH avaliado por meio do índice kappa foi considerada moderada, variando de 0,42 a 0,58 (FCH-IDF entre os homens) (Tabela 5). Os valores de sensibilidade e especificidade para SM foram relativamente maiores para as medidas de FCH estabelecidas pelo NCEP do que aquelas definidas pela IDF, com sensibilidade de 94\% e 98,3\% entre mulheres e homens, respectivamente, e especificidade de $80,3 \%$ e 74,5\% (Tabela 5).

Encontraram-se valores elevados de especificidade para todos os indicadores de risco cardiometabólico, sobretudo entre participantes do sexo feminino, com valores superiores a 70\%. O indicador 
Tabela 1

Distribuição dos participantes segundo variáveis sociodemográficas e comportamentais, de acordo com sexo e fenótipo cintura hipertrigliceridêmica. ELSA-Brasil, 2008-2010

\begin{tabular}{|c|c|c|c|c|c|c|c|c|c|c|}
\hline \multirow[t]{3}{*}{ Variáveis } & \multicolumn{5}{|c|}{ Sexo feminino } & \multicolumn{5}{|c|}{ Sexo masculino } \\
\hline & \multirow[t]{2}{*}{$\mathbf{n}$} & \multicolumn{2}{|c|}{ FCH-IDF } & \multicolumn{2}{|c|}{ FCH-NCEP } & \multirow[t]{2}{*}{$\mathbf{n}$} & \multicolumn{2}{|c|}{ FCH-IDF } & \multicolumn{2}{|c|}{ FCH-NCEP } \\
\hline & & $\%$ & Valor de $p$ & $\%$ & Valor de $p$ & & $\%$ & Valor de $p$ & $\%$ & Valor de $p$ \\
\hline \multicolumn{11}{|l|}{ Sociodemográficas } \\
\hline \multicolumn{11}{|l|}{ Grupo etário (anos) } \\
\hline $35-44$ & 1.696 & 11,6 & $<0,001$ & 7,8 & $<0,001$ & 1.473 & 25,5 & $<0,001$ & 9,3 & $<0,001$ \\
\hline $45-54$ & 2.887 & 18,8 & & 13,2 & & 2.380 & 33,5 & & 13,6 & \\
\hline $55-64$ & 1.829 & 24,5 & & 17,4 & & 1.484 & 35,0 & & 15,4 & \\
\hline $65-74$ & 530 & 24,5 & & 19,1 & & 532 & 30,1 & & 13,9 & \\
\hline \multicolumn{11}{|l|}{ Escolaridade } \\
\hline Até Fundamental incompleto & 259 & 31,3 & $<0,001$ & 23,2 & $<0,001$ & 480 & 32,3 & 0,241 & 12,5 & 0,117 \\
\hline Fundamental completo & 375 & 22,3 & & 20,3 & & 500 & 34,2 & & 15,6 & \\
\hline Médio completo & 2.497 & 21,2 & & 14,7 & & 2.029 & 32,4 & & 11,9 & \\
\hline Superior completo & 3.811 & 16,1 & & 11,3 & & 2.860 & 30,4 & & 13,5 & \\
\hline \multicolumn{11}{|l|}{ Cor/Raça } \\
\hline Preta & 1.231 & 17,5 & 0,137 & 12,8 & 0,202 & 842 & 30,1 & 0,462 & 10,6 & 0,006 \\
\hline Parda & 1.887 & 20,9 & & 14,9 & & 1.812 & 31,4 & & 12,4 & \\
\hline Branca & 3.507 & 18,5 & & 13,1 & & 2.948 & 32,2 & & 14,2 & \\
\hline Amarela & 193 & 19,2 & & 10,4 & & 104 & 26,9 & & 5,8 & \\
\hline Indígena & 55 & 21,8 & & 14,6 & & 81 & 37,0 & & 17,3 & \\
\hline \multicolumn{11}{|l|}{ Situação conjugal } \\
\hline Solteiro & 943 & 13,7 & $<0,001$ & 13,0 & $<0,001$ & 319 & 24,1 & 0,007 & 13,3 & 0,595 \\
\hline Viúvo & 434 & 26,3 & & 14,8 & & 68 & 23,5 & & 12,8 & \\
\hline Casado/Com companheiro & 3.755 & 18,5 & & 10,0 & & 4.766 & 32,2 & & 11,0 & \\
\hline Separado/Divorciado & 1.506 & 20,7 & & 17,7 & & 587 & 32,5 & & 8,8 & \\
\hline Outro & 304 & 23,0 & & 17,1 & & 129 & 24,8 & & 13,3 & \\
\hline \multicolumn{11}{|l|}{ Seguro saúde } \\
\hline $\operatorname{Sim}$ & 4.963 & 18,1 & 0,003 & 12,8 & 0,013 & 3.654 & 31,8 & 0,547 & 13,7 & 0,046 \\
\hline Não & 1.978 & 21,2 & & 15,1 & & 2.214 & 31,1 & & 11,9 & \\
\hline \multicolumn{11}{|l|}{ Comportamentais } \\
\hline \multicolumn{11}{|l|}{ Atividade física } \\
\hline Ativo & 2.254 & 15,5 & $<0,001$ & 10,7 & $<0,001$ & 2.536 & 27,2 & $<0,001$ & 10,0 & $<0,001$ \\
\hline Inativo & 4.568 & 20,7 & & 14,9 & & 3.255 & 35,0 & & 15,4 & \\
\hline \multicolumn{11}{|l|}{ Consumo excessivo de álcool } \\
\hline Não & 6.679 & 18,6 & $<0,001$ & 13,2 & $<0,001$ & 5.143 & 30,0 & $<0,001$ & 12,2 & $<0,001$ \\
\hline Sim & 247 & 28,7 & & 21,9 & & 720 & 42,8 & & 20,1 & \\
\hline \multicolumn{11}{|l|}{ Tabagismo } \\
\hline Nunca fumou & 4.369 & 16,8 & $<0,001$ & 11,7 & $<0,001$ & 3.034 & 26,5 & $<0,001$ & 10,3 & $<0,001$ \\
\hline Fumante & 869 & 23,8 & & 15,7 & & 888 & 36,2 & & 13,6 & \\
\hline Ex-fumante & 1.704 & 22,1 & & 16,8 & & 1.946 & 37,3 & & 17,0 & \\
\hline
\end{tabular}

FCH-IDF: fenótipo cintura hipertrigliceridêmica segundo os pontos de corte da Federação Internacional de Diabetes; FCH-NCEP: fenótipo cintura hipertrigliceridêmica segundo os pontos de corte do Programa Nacional de Educação sobre o Colesterol dos Estados Unidos.

com maior especificidade entre mulheres foi o escore de Framingham (94,7\% para FCH-IDF), e entre os homens, o índice HOMA-IR (82,5\% para FCH-IDF). 
Tabela 2

Distribuição dos participantes segundo variáveis de saúde e indicadores cardiovasculares e metabólicos, de acordo com sexo e fenótipo cintura hipertrigliceridêmica. ELSA-Brasil, 2008-2010.

\begin{tabular}{|c|c|c|c|c|c|c|c|c|c|c|}
\hline \multirow[t]{3}{*}{ Variáveis } & \multicolumn{5}{|c|}{ Sexo feminino } & \multicolumn{5}{|c|}{ Sexo masculino } \\
\hline & \multirow[t]{2}{*}{$\mathbf{n}$} & \multicolumn{2}{|c|}{ FCH-IDF } & \multicolumn{2}{|c|}{ FCH-NCEP } & \multirow[t]{2}{*}{$\mathbf{n}$} & \multicolumn{2}{|c|}{ FCH-IDF } & \multicolumn{2}{|c|}{ FCH-NCEP } \\
\hline & & $\%$ & Valor de $p$ & $\%$ & Valor de $p$ & & $\%$ & Valor de $p$ & $\%$ & Valor de $p$ \\
\hline \multicolumn{11}{|l|}{ Saúde } \\
\hline \multicolumn{11}{|l|}{ Hipertensão } \\
\hline Não & 5.000 & 14,9 & $<0,001$ & 9,7 & $<0,001$ & 3.783 & 25,5 & $<0,001$ & 8,5 & $<0,001$ \\
\hline Sim & 1.939 & 29,6 & & 23,2 & & 2.079 & 42,4 & & 21,1 & \\
\hline \multicolumn{11}{|l|}{ Diabetes } \\
\hline Não & 6.000 & 16,0 & $<0,001$ & 10,6 & $<0,001$ & 4.667 & 27,5 & $<0,001$ & 10,1 & $<0,001$ \\
\hline Sim & 942 & 38,2 & & 31,6 & & 1.201 & 47,3 & & 24,5 & \\
\hline \multicolumn{11}{|l|}{ DCV } \\
\hline Não & 5.820 & 18,5 & $<0,001$ & 13,1 & $<0,001$ & 4.912 & 31,2 & 0,002 & 12,5 & $<0,001$ \\
\hline Sim & 298 & 30,5 & & 24,5 & & 314 & 39,5 & & 21,7 & \\
\hline \multicolumn{11}{|l|}{ Doenças renais } \\
\hline Não & 6.707 & 18,6 & $<0,001$ & 13,2 & 0,001 & 5.606 & 31,1 & 0,001 & 12,7 & $<0,001$ \\
\hline Sim & 234 & 28,6 & & 20,5 & & 263 & 41,1 & & 20,9 & \\
\hline \multicolumn{11}{|l|}{ Autopercepção de saúde } \\
\hline Bom & 5.703 & 17,2 & $<0,001$ & 11,6 & $<0,001$ & 4.795 & 29,5 & $<0,001$ & 11,4 & $<0,001$ \\
\hline Regular & 1.100 & 26,6 & & 21,5 & & 993 & 40,6 & & 19,7 & \\
\hline Ruim & 138 & 33,3 & & 26,1 & & 79 & 40,5 & & 24,1 & \\
\hline \multicolumn{11}{|l|}{ IMC } \\
\hline Baixo peso & 73 & 0,0 & 0,000 & 0,0 & 0,000 & 63 & 0,0 & 0,000 & 0,0 & $<0,001$ \\
\hline Peso normal & 2.857 & 6,8 & & 1,2 & & 2.056 & 8,7 & & 0,1 & \\
\hline Sobrepeso & 2.480 & 23,6 & & 15,0 & & 2.657 & 39,9 & & 9,0 & \\
\hline Obesidade & 1.532 & 35,3 & & 34,5 & & 1.093 & 56,1 & & 47,9 & \\
\hline \multicolumn{11}{|l|}{$\mathrm{HDL}$} \\
\hline Desejável & 3.374 & 10,6 & $<0,001$ & 7,0 & $<0,001$ & 1.063 & 13,0 & $<0,001$ & 4,5 & $<0,001$ \\
\hline Limítrofe & 3.392 & 26,2 & & 19,0 & & 3.962 & 32,9 & & 13,1 & \\
\hline Baixo & 176 & 41,5 & & 30,1 & & 844 & 48,7 & & 23,0 & \\
\hline Não-HDL & & & & & & & & & & \\
\hline Normal & 3.949 & 8,4 & $<0,001$ & 5,7 & $<0,001$ & 2.801 & 17,5 & $<0,001$ & 7,4 & $<0,001$ \\
\hline Aumentado & 2.993 & 32,9 & & 23,7 & & 3.067 & 44,4 & & 18,2 & \\
\hline PCR & & & & & & & & & & \\
\hline Normal & 4.684 & 14,3 & $<0,001$ & 8,7 & $<0,001$ & 4.503 & 28,9 & $<0,001$ & 10,7 & $<0,001$ \\
\hline Aumentado & 2.258 & 28,8 & & 23,4 & & 1.366 & 40,3 & & 20,6 & \\
\hline História familiar de doenças & & & & & & & & & & \\
\hline Nenhuma & 565 & 14,2 & $<0,001$ & 9,0 & $<0,001$ & 866 & 26,4 & $<0,001$ & 10,9 & 0,021 \\
\hline Uma & 1.567 & 16,8 & & 11,2 & & 1.559 & 29,4 & & 12,1 & \\
\hline Duas ou mais & 4.810 & 20,3 & & 14,7 & & 3.444 & 33,8 & & 14,0 & \\
\hline Menopausa & & & & & & & & & & \\
\hline Não & 3.456 & 14,4 & $<0,001$ & 10,0 & $<0,001$ & & & & & \\
\hline Sim (natural) & 2.382 & 22,8 & & 16,2 & & & & & & \\
\hline Sim (cirúrgica) & 972 & 26,0 & & 19,6 & & & & & & \\
\hline Outros & 113 & 19,5 & & 11,5 & & & & & & \\
\hline Indicadores & & & & & & & & & & \\
\hline Escore de Framingham & & & & & & & & & & \\
\hline Baixo risco & 6.456 & 17,5 & $<0,001$ & 12,1 & $<0,001$ & 4.153 & 26,8 & $<0,001$ & 9,6 & $<0,001$ \\
\hline Alto risco & 486 & 38,7 & & 32,1 & & 1.716 & 43,1 & & 21,4 & \\
\hline Índice HOMA-IR & & & & & & & & & & \\
\hline Não resistente a insulina & 5.696 & 14,3 & $<0,001$ & 8,8 & $<0,001$ & 4.271 & 22,5 & $<0,001$ & 6,1 & $<0,001$ \\
\hline Resistente a insulina & 1.246 & 40,5 & & 34,7 & & 1.598 & 55,9 & & 31,4 & \\
\hline SM & & & & & & & & & & \\
\hline Ausência & 4.396 & 2,7 & $<0,001$ & 1,2 & $<0,001$ & 2.913 & 2,5 & $<0,001$ & 0,3 & $<0,001$ \\
\hline Presença & 2.540 & 47,2 & & 42,6 & & 2.950 & 60,2 & & 36,5 & \\
\hline
\end{tabular}

DCV: doenças cardiovasculares; FCH-IDF: fenótipo cintura hipertrigliceridêmica segundo os pontos de corte da Federação Internacional de Diabetes; FCH-NCEP: fenótipo cintura hipertrigliceridêmica segundo os pontos de corte do Programa Nacional de Educação sobre o Colesterol dos Estados Unidos; HDL: lipoproteína de alta densidade; HOMA-IR: modelo de avaliação da homeostase da resistência à insulina; IMC: índice de massa corporal; PCR: proteína C reativa; SM: síndrome metabólica. 
Tabela 3

Fatores associados ao fenótipo cintura hipertrigliceridêmica segundo os pontos de corte da Federação Internacional de Diabetes (FCH-IDF) e segundo os pontos de corte do Programa Nacional de Educação sobre o Colesterol dos Estados Unidos (FCH-NCEP) entre mulheres. ELSA-Brasil, $2008-2010$.

\begin{tabular}{|c|c|c|c|c|}
\hline \multirow[t]{2}{*}{ Fatores } & \multicolumn{2}{|c|}{ FCH-IDF } & \multicolumn{2}{|c|}{ FCH-NCEP } \\
\hline & OR bruta (IC95\%) & OR ajustada (IC95\%) & OR bruta (IC95\%) & OR ajustada (IC95\%) \\
\hline \multicolumn{5}{|l|}{ Sociodemográficos } \\
\hline \multicolumn{5}{|l|}{ Grupo etário (anos) } \\
\hline $35-44$ & 1,00 * & 1,00 * & 1,00 * & 1,00 * \\
\hline $45-54$ & $1,78(1,49-2,12)$ & $1,27(1,03-1,57)$ & $1,81(1,47-2,22)$ & $1,26(0,99-1,61)$ \\
\hline $55-64$ & $2,48(2,07-2,98)$ & $1,52(1,16-1,98)$ & $2,50(2,02-3,10)$ & $1,49(1,10-2,02)$ \\
\hline $65-74$ & $2,49(1,94-3,19)$ & $1,56(1,12-2,18)$ & $2,79(2,11-3,69)$ & $1,77(1,21-2,58)$ \\
\hline \multicolumn{5}{|l|}{ Nível de escolaridade } \\
\hline Superior completo & 1,00 * & 1,00 * & 1,00 * & 1,00 * \\
\hline Médio completo & $1,40(1,23-1,60)$ & $1,19(1,02-1,39)$ & $1,34(1,16-1,56)$ & $1,11(0,93-1,32)$ \\
\hline Até Fundamental completo & $2,01(1,65-2,43)$ & $1,30(1,02-1,66)$ & $2,14(1,72-2,65)$ & $1,32(1,01-1,73)$ \\
\hline \multicolumn{5}{|l|}{ Situação conjugal } \\
\hline Solteira & 1,00 * & 1,00 * & 1,00 * & 1,00 * \\
\hline Separada/Viúva & $1,79(1,45-2,21)$ & $1,34(1,06-1,70)$ & $1,68(1,32-2,14)$ & $1,23(0,94-1,61)$ \\
\hline Casada/Com companheiro & $1,43(1,17-1,75)$ & $1,29(1,03-1,61)$ & $1,35(1,07-1,70)$ & $1,20(0,93-1,55)$ \\
\hline \multicolumn{5}{|l|}{ Seguro saúde } \\
\hline Sim & 1,00 * & 1,00 * & 1,00 * & 1,00 * \\
\hline Não & $0,82(0,72-0,94)$ & $1,03(0,87-1,20)$ & $0,83(0,71-0,96)$ & $1,02(0,86-1,23)$ \\
\hline \multicolumn{5}{|l|}{ Comportamentais } \\
\hline \multicolumn{5}{|l|}{ Atividade física } \\
\hline Ativo & 1,00 * & 1,00 * & 1,00 * & 1,00 * \\
\hline Inativo & $1,42(1,24-1,62)$ & $1,16(0,99-1,35)$ & $1,47(1,26-1,72)$ & $1,16(0,97-1,38)$ \\
\hline \multicolumn{5}{|l|}{ Consumo de álcool excessivo } \\
\hline Não & 1,00 * & 1,00 * & 1,00 * & 1,00 * \\
\hline $\operatorname{Sim}$ & $1,76(1,33-2,34)$ & $2,09(1,50-2,91)$ & $1,85(1,35-2,52)$ & $2,21(1,54-3,17)$ \\
\hline \multicolumn{5}{|l|}{ Tabagismo } \\
\hline Nunca fumou & 1,00 * & 1,00 * & 1,00 * & 1,00 * \\
\hline Ex-fumante & $1,40(1,22-1,61)$ & $1,21(1,03-1,42)$ & $1,52(1,30-1,78)$ & $1,31(1,09-1,57)$ \\
\hline Fumante & $1,55(1,30-1,84)$ & $1,04(0,85-1,28)$ & $1,40(1,14-1,72)$ & $0,91(0,72-1,16)$ \\
\hline \multicolumn{5}{|l|}{ Variáveis de saúde } \\
\hline \multicolumn{5}{|l|}{ Doenças renais } \\
\hline Não & 1,00 * & 1,00 * & 1,00 * & 1,00 * \\
\hline Sim & $1,75(1,31-2,34)$ & $1,31(0,94-1,83)$ & $1,70(1,23-2,35)$ & $1,16(0,80-1,69)$ \\
\hline \multicolumn{5}{|l|}{ Autopercepção de saúde } \\
\hline Bom & 1,00 * & 1,00 * & 1,00 * & 1,00 * \\
\hline Regular & $1,74(1,50-2,02)$ & $1,30(1,09-1,54)$ & $2,08(1,76-2,45)$ & $1,55(1,28-1,87)$ \\
\hline Ruim & $2,41(1,68-3,46)$ & $1,76(1,17-2,66)$ & $2,69(1,82-3,96)$ & $1,90(1,22-2,95)$ \\
\hline \multicolumn{5}{|l|}{$\mathrm{HDL}$} \\
\hline Desejável & 1,00 * & 1,00 * & 1,00 * & 1,00 * \\
\hline Limítrofe & $3,00(2,62-3,43)$ & $2,96(2,56-3,43)$ & $3,14(2,68-3,68)$ & $3,00(2,53-3,56)$ \\
\hline Baixo & $6,00(4,35-8,24)$ & $9,19(6,36-13,26)$ & $5,76(4,06-8,15)$ & $7,63(5,10-11,40)$ \\
\hline \multicolumn{5}{|l|}{ Não-HDL } \\
\hline Normal & 1,00 * & 1,00 * & 1,00 * & 1,00 * \\
\hline Aumentado & $5,35(4,67-6,13)$ & $5,03(4,33-5,84)$ & $5,17(4,41-6,06)$ & $4,69(3,94-5,58)$ \\
\hline \multicolumn{5}{|l|}{ PCR } \\
\hline Normal & 1,00 * & 1,00 * & 1,00 * & 1,00 * \\
\hline Aumentado & $2,43(2,15-2,75)$ & $1,94(1,69-2,22)$ & $3,22(2,79-3,70)$ & $2,56(2,19-2,99)$ \\
\hline \multicolumn{5}{|l|}{ História familiar de doenças } \\
\hline Nenhuma & 1,00 * & 1,00 * & 1,00 * & 1,00 * \\
\hline Uma ou mais & $1,46(1,14-1,87)$ & $1,27(0,97-1,65)$ & $1,62(1,20-2,18)$ & $1,39(1,01-1,91)$ \\
\hline \multicolumn{5}{|l|}{ Menopausa } \\
\hline Não menopausadas & 1,00 * & 1,00 * & 1,00 * & 1,00 * \\
\hline Menopausadas & $1,84(1,63-2,08)$ & $1,10(0,91-1,33)$ & $1,85(1,61-2,14)$ & $1,06(0,86-1,32)$ \\
\hline
\end{tabular}

HDL: lipoproteína de alta densidade; IC95\%: intervalo de 95\% de confiança; OR: odds ratio; PCR: proteína C reativa.

* Grupo de referência. 


\section{Tabela 4}

Fatores associados ao fenótipo cintura hipertrigliceridêmica segundo os pontos de corte da Federação Internacional de Diabetes (FCH-IDF) e segundo os pontos de corte do Programa Nacional de Educação sobre o Colesterol dos Estados Unidos (FCH-NCEP) entre homens. ELSA-Brasil, 2008-2010.

\begin{tabular}{|c|c|c|c|c|}
\hline \multirow[t]{2}{*}{ Fatores } & \multicolumn{2}{|c|}{ FCH-IDF } & \multicolumn{2}{|c|}{ FCH-NCEP } \\
\hline & OR bruta (IC95\%) & OR ajustada (IC95\%) & OR bruta (IC95\%) & OR ajustada (IC95\%) \\
\hline \multicolumn{5}{|l|}{ Sociodemográficos } \\
\hline \multicolumn{5}{|l|}{ Grupo etário (anos) } \\
\hline $35-44$ & 1,00 * & 1,00 * & 1,00 * & 1,00 * \\
\hline $45-54$ & $1,48(1,28-1,71)$ & $1,19(1,01-1,41)$ & $1,54(1,24-1,90)$ & $1,22(0,97-1,54)$ \\
\hline $55-64$ & $1,57(1,34-1,85)$ & $1,30(1,08-1,56)$ & $1,78(1,42-2,23)$ & $1,38(1,07-1,77)$ \\
\hline $65-74$ & $1,26(1,01-1,57)$ & $1,13(0,88-1,47)$ & $1,58(1,17-2,13)$ & $1,22(0,86-1,72)$ \\
\hline \multicolumn{5}{|l|}{ Situação conjugal } \\
\hline Solteiro & $1,00 *$ & $1,00 *$ & & \\
\hline Separado/Viúvo & $1,38(1,02-1,86)$ & $1,19(0,85-1,66)$ & & \\
\hline Casado/Com companheiro & $1,50(1,15-1,95)$ & $1,29(0,96-1,73)$ & & \\
\hline \multicolumn{5}{|l|}{ Cor/Raça } \\
\hline Preta & & & 1,00 * & $1,00 *$ \\
\hline Parda & & & $1,20(0,93-1,56)$ & $1,14(0,86-1,50)$ \\
\hline Branca & & & $1,39(1,09-1,78)$ & $1,47(1,13-1,91)$ \\
\hline Amarela & & & $0,52(0,22-1,22)$ & $0,63(0,26-1,50)$ \\
\hline Indígena & & & $1,77(0,95-3,28)$ & $1,60(0,83-3,06)$ \\
\hline \multicolumn{5}{|l|}{ Seguro saúde } \\
\hline Sim & & & 1,00 * & 1,00 * \\
\hline Não & & & $1,18(1,00-1,38)$ & $1,35(1,13-1,61)$ \\
\hline \multicolumn{5}{|l|}{ Comportamentais } \\
\hline \multicolumn{5}{|l|}{ Atividade física } \\
\hline Ativo & 1,00 * & 1,00 * & 1,00 * & 1,00 * \\
\hline Inativo & $1,44(1,29-1,61)$ & $1,27(1,12-1,44)$ & $1,64(1,40-1,92)$ & $1,41(1,19-1,68)$ \\
\hline \multicolumn{5}{|l|}{ Consumo de álcool excessivo } \\
\hline Não & 1,00 * & 1,00 * & 1,00 * & 1,00 * \\
\hline Sim & $1,75(1,49-2,05)$ & $1,93(1,60-2,32)$ & $1,85(1,52-2,27)$ & $1,98(1,58-2,49)$ \\
\hline \multicolumn{5}{|l|}{ Tabagismo } \\
\hline Nunca fumou & 1,00 * & 1,00 * & 1,00 * & 1,00 * \\
\hline Ex-fumante & $1,64(1,46-1,86)$ & $1,43(1,24-1,64)$ & $1,79(1,51-2,11)$ & $1,46(1,22-1,76)$ \\
\hline Fumante & $1,57(1,34-1,84)$ & $1,16(0,97-1,39)$ & $1,38(1,10-1,72)$ & $0,93(0,73-1,20)$ \\
\hline \multicolumn{5}{|l|}{ Variáveis de saúde } \\
\hline \multicolumn{5}{|l|}{ Doenças renais } \\
\hline Não & 1,00 * & 1,00 * & 1,00 * & 1,00 * \\
\hline Sim & $1,54(1,20-1,99)$ & $1,17(0,87-1,56)$ & $1,83(1,34-2,48)$ & $1,30(0,92-1,85)$ \\
\hline \multicolumn{5}{|l|}{ Autopercepção de saúde } \\
\hline Bom & 1,00 * & 1,00 * & 1,00 * & 1,00 * \\
\hline Regular & $1,63(1,42-1,88)$ & $1,40(1,20-1,64)$ & $1,91(1,59-2,28)$ & $1,65(1,36-2,02)$ \\
\hline Ruim & $1,63(1,03-2,56)$ & $1,29(0,78-2,15)$ & $2,45(1,45-4,14)$ & $2,41(1,36-4,26)$ \\
\hline \multicolumn{5}{|l|}{ HDL } \\
\hline Desejável & 1,00 * & 1,00 * & 1,00 * & 1,00 * \\
\hline Limítrofe & $3,29(2,71-3,98)$ & $3,35(2,73-4,10)$ & $3,21(2,37-4,35)$ & $3,06(2,23-4,20)$ \\
\hline Baixo & $6,36(5,09-7,96)$ & $9,04(7,05-11,59)$ & $6,31(4,53-8,79)$ & $7,25(5,01-10,32)$ \\
\hline \multicolumn{5}{|l|}{ Não-HDL } \\
\hline Normal & 1,00 * & 1,00 * & 1,00 * & 1,00 * \\
\hline Aumentado & $3,78(3,35-4,26)$ & $4,30(3,77-4,91)$ & $2,78(2,35-3,29)$ & $2,94(2,45-3,53)$ \\
\hline \multicolumn{5}{|l|}{ PCR } \\
\hline Normal & 1,00 * & 1,00 * & 1,00 * & 1,00 * \\
\hline Aumentado & $1,66(1,47-1,89)$ & $1,34(1,16-1,54)$ & $2,17(1,85-2,55)$ & $1,77(1,48-2,11)$ \\
\hline \multicolumn{5}{|l|}{ História familiar de doenças } \\
\hline Nenhuma & 1,00 * & 1,00 * & 1,00 * & 1,00 * \\
\hline Uma ou mais & $1,34(1,14-1,57)$ & $1,26(1,06-1,51)$ & $1,27(1,01-1,60)$ & $1,19(0,93-1,52)$ \\
\hline
\end{tabular}

HDL: lipoproteína de alta densidade; IC95\%: intervalo de 95\% de confiança; OR: odds ratio; PCR: proteína C reativa.

* Grupo de referência. 
Tabela 5

Comparação entre fenótipo cintura hipertrigliceridêmica e indicadores de doenças cardiovasculares e metabólicas. ELSA-Brasil, 2008-2010.

\begin{tabular}{|c|c|c|c|c|}
\hline & Correlação * & Índice kappa & $\begin{array}{c}\text { Sensibilidade } \\
\%(\text { IC95\%) }\end{array}$ & $\begin{array}{c}\text { Especificidade } \\
\%(\text { IC95\%) }\end{array}$ \\
\hline \multicolumn{5}{|l|}{ Sexo feminino } \\
\hline \multicolumn{5}{|l|}{$\mathrm{FCH}-\mathrm{IDF}$} \\
\hline SM & 0,84 & 0,50 & $91,1(90,5-91,8)$ & $76,2(75,2-77,2)$ \\
\hline Escore de Framingham & 0,32 & 0,12 & $14,3(13,4-15,1)$ & $94,7(94,2-95,2)$ \\
\hline Índice HOMA-IR & 0,45 & 0,26 & $38,2(37,2-39,5)$ & $86,3(86,0-87,6)$ \\
\hline \multicolumn{5}{|l|}{ FCH-NCEP } \\
\hline SM & 0,88 & 0,49 & $94,0(93,5-94,6)$ & $80,3(79,3-81,2)$ \\
\hline Escore de Framingham & 0,35 & 0,14 & $16,7(15,8-17,6)$ & $94,5(94,0-95,0)$ \\
\hline Índice HOMA-IR & 0,52 & 0,29 & $46,3(45,1-47,4)$ & $86,5(85,7-87,3)$ \\
\hline \multicolumn{5}{|l|}{ Sexo masculino } \\
\hline \multicolumn{5}{|l|}{ FCH-IDF } \\
\hline SM & 0,90 & 0,58 & $96,0(95,5-96,5)$ & $70,8(69,6-71,9)$ \\
\hline Escore de Framingham & 0,27 & 0,16 & $40,0(38,7-41,2)$ & $75,7(74,6-76,8)$ \\
\hline Índice HOMA-IR & 0,51 & 0,32 & $48,2(46,9-49,5)$ & $82,5(81,5-83,4)$ \\
\hline \multicolumn{5}{|l|}{ FCH-NCEP } \\
\hline SM & 0,91 & 0,42 & $98,3(98,0-98,6)$ & $74,5(73,3-75,6)$ \\
\hline Escore de Framingham & 0,31 & 0,14 & $48,0(46,8-49,3)$ & $73,6(72,5-74,7)$ \\
\hline Índice HOMA-IR & 0,59 & 0,30 & $65,7(64,5-66,9)$ & $78,5(77,5-79,6)$ \\
\hline
\end{tabular}

FCH-IDF: fenótipo cintura hipertrigliceridêmica segundo os pontos de corte da Federação Internacional de Diabetes; FCH-NCEP: fenótipo cintura hipertrigliceridêmica segundo os pontos de corte do Programa Nacional de Educação sobre o Colesterol dos Estados Unidos; HOMA-IR: modelo de avaliação da homeostase da resistência à insulina; IC95\%: intervalo de \%95 de confiança; SM: síndrome metabólica.

* A correlação foi avaliada por meio da matriz tetracórica.

\section{Discussão e conclusões}

A população do ELSA-Brasil, composta por homens e mulheres de meia idade e idosos, apresentou uma prevalência do FCH que variou de 13,3\% a 24,7\%, a depender da classificação da CC utilizada. Em outros estudos desenvolvidos com brasileiros, tal percentual variou de aproximadamente 5\% a 33\%, porém todos foram realizados com populações específicas distintas, tanto em relação a sexo e idade, quanto à região do país 5,29,30. Estudos com população de faixa etária mais similar foram realizados nas cidades de Viçosa (Minas Gerais) e Salvador (Bahia). Com pontos de corte definidos de acordo a IDF, apresentaram prevalência mais próximas às encontradas neste estudo, de aproximadamente 17,3 e $20,5 \%$, respectivamente 4,6 .

De acordo com os pontos de corte definidos pela IDF, as prevalências apresentaram diferenças entre sexo, o que não foi observado para classificação do NCEP. Apesar de a maioria dos estudos não evidenciarem distinções entre homens e mulheres 4,30, um estudo no Peru, que utilizou o ponto de corte da IDF para CC, identificou maior proporção de homens com FCH $(38,1 \%$ comparado a 30,3\% em mulheres) 31. Já foi descrito que, entre os homens, as concentrações de apolipoproteína B, relacionadas à aterogênese e ao surgimento de DCV, elevam-se rapidamente até a CC se aproximar de $100 \mathrm{~cm}$, e depois permanecem estáveis 2 . Esse fato pode explicar alta prevalência do risco cardiovascular entre homens nessa zona de transição do ponto de corte da CC. Além disso, um estudo expôs que a diferença entre sexo encontrada na prevalência de marcadores como a SM foi atribuída, particularmente, à obesidade abdominal mensurada pela CC 32.

Estudos revelam que a CC aumentada associada à hipertrigliceridemia em jejum podem ser utilizadas na identificação de indivíduos com obesidade abdominal e, consequentemente, na predição de 
DCV e metabólicas 4,33. Contudo, não existe um consenso quanto aos pontos de corte e, assim, optouse por avaliar o FCH de acordo com as duas indicações de CC mais utilizadas no Brasil.

A classificação mais adotada no Brasil é a estabelecida pelo NCEP, também referenciada nas diretrizes de hipertensão e SM 34,35. A Organização Mundial da Saúde (OMS) menciona esses valores, mas inclui 102 e 88 no ponto de corte 36 . No entanto, autores criticaram-no por considerá-lo demasiadamente alto, podendo levar a uma classificação errônea e subestimação da prevalência 3,37.

Em paralelo a isso, a maioria dos estudos brasileiros que investigaram FCH utilizaram como ponto de corte os critérios definidos pela IDF para latino-americanos 4,6. Ainda que essa definição não tenha sido estabelecida especificamente para brasileiros, ela levou em consideração a raça/etnia, fator que influencia medidas antropométricas como a CC 12. O estudo no qual o FCH foi proposto também indicou o ponto de corte da CC para homens $\geq 90 \mathrm{~cm}^{2}$.

Além das discussões que visam identificar um valor ideal da CC para melhor predizer o risco cardiometabólico, é importante ter em conta também o local em que essa medida é realizada. A IDF e a OMS definem o ponto médio entre a última costela e a crista ilíaca, como foi realizado com a população do ELSA-Brasil. Já o NCEP determina que a CC deve ser medida imediatamente acima da crista ilíaca. Em um estudo realizado em asiáticos 38, percebeu-se que os valores médios de CC diferiam de acordo com o local onde a medida era realizada, e que apesar de possuírem uma capacidade semelhante para triagem de fatores de risco metabólicos, as medidas poderiam ser superestimadas ou subestimadas caso não fossem feitas no local especificado pelas orientações correspondentes.

Apesar da indefinição quanto aos pontos de corte, a associação do FCH com fatores de risco cardiovasculares e metabólicos foi confirmada no presente estudo e independe dos critérios utilizados para sua definição. As variáveis que demonstraram associação com o FCH são fatores modificáveis, o que indica que grande parte desse risco pode ser minimizada com a adoção de um estilo de vida saudável.

Todos os modelos, feminino e masculino e com CC determinada pela IDF ou NCEP, apresentaram associação do FCH com fatores comportamentais como consumo excessivo de álcool e ser ex-fumante. Essa associação com o tabagismo foi demonstrada em outras pesquisas realizadas na população brasileira 5,30, e pode ser relacionada ao fato de que ex-fumantes apresentam maiores índices de sobrepeso e obesidade avaliadas por meio do IMC e CC 39. O FCH foi associado à inatividade física entre os homens, assim como foi descrito anteriormente 40,41, comprovando a importância da atividade física na redução dos riscos cardiometabólicos.

Com a obesidade, especialmente a visceral, ocorre a disfunção dos adipócitos e a consequente liberação de adipocinas pró-inflamatórias que acarretam em disfunção endotelial, remodelação vascular sistêmica, aterosclerose, alterações dislipidêmicas e subsequente hipertensão arterial, além da resistência à insulina e diabetes mellitus tipo 2 42. A relação entre FCH e obesidade pode explicar as demais associações encontradas no presente estudo como níveis elevados de não-HDL e PCR, e baixos de HDL. Essas associações foram comprovadas em pesquisas anteriores 4,30,43. O estado inflamatório provocado pelos adipócitos hipertrofiados explica a associação de FCH com a PCR 44,45.

Outros fatores associados com FCH foram a história familiar de doenças cardiovasculares e metabólicas e a autopercepção do estado de saúde negativa, que foram corroborados por outras pesquisas 40,46. Além da relação com FCH, a autopercepção de saúde também foi associada a outros fatores como tabagismo, níveis elevados de PCR e glicose em jejum, o que pode explicar a própria relação com o FCH 46.

A idade foi associada ao FCH em todos os modelos, e nível de escolaridade nos modelos femininos. Essa associação foi encontrada anteriormente em uma cidade da Espanha 41, na qual a prevalência do FCH era similar à desta investigação. Entre as mulheres, a prevalência e a chance de ocorrência do FCH aumentou gradativamente com a idade e entre os homens foi mais acentuada no grupo etário de 55 a 64 anos. O aumento dessas proporções até os 64 anos e declínio após os 65 anos pode sugerir que indivíduos que tenham sofrido várias décadas de carga lipídica excessiva apresentem, eventualmente, taxas de mortalidade mais elevadas 43.

Ao comparar o FCH com outros indicadores é importante relativizar os resultados à medida que eles possuem críticas e discussões quanto aos pontos de corte, além de avaliar o risco cardiovascular ou metabólico individualmente 3,47 . Como a SM, o FCH se propõe a predizer o risco cardiometabólico, que se refere ao risco global de DCV resultante da presença de fatores de risco tradicionais, com- 
binados à possível contribuição adicional de fatores metabólicos 47. Apesar de ser um indicador mais recente, e por isso menos conhecido, alguns estudos sugerem que o FCH pode ser tão discriminante quanto a SM 3 , usando diferentes critérios (NCEP e IDF) 3,48.

Apesar de as variáveis que determinam o FCH estarem contidas no indicador SM, os altos valores de correlação entre elas, como apresentado no presente estudo, são base para ratificar que apenas duas medidas - CC e TG - identificam o risco cardiometabólico de maneira similar e mais simples e econômica. Dos critérios para definir SM, CC e TG são as variáveis que melhor discriminam a resistência à insulina e adiposidade visceral 49 . Portanto, indicadores de custo mais alto como a SM podem ser substituídos pelo FCH em populações de diferentes faixas etárias 50.

A concordância do FCH com SM, avaliada por meio do índice kappa, foi considerada moderada, similar ao encontrado em outras pesquisas 31,41. É importante considerar que esse índice mede a concordância que não ocorreu ao acaso. A população do ELSA-Brasil em diversos aspectos pode ser considerada mais saudável que a população geral, uma vez que a maioria possui maior assistência médica e especificamente para este estudo em decorrência dos critérios de exclusão. Esse fato, além de não se ter uma amostra probabilística, pode ter subestimado os valores apresentados pelo índice kappa.

Os valores de sensibilidade e especificidade da SM foram relativamente mais elevados para FCH definido pela NCEP do que pela IDF. Todavia, assumir este como melhor ponto de corte do FCH seria afirmar que eles são de fato diferentes, o que não foi testado neste estudo. Pode-se entender que independentemente dos critérios utilizados para definir $\mathrm{FCH}$, este é um bom indicador do risco cardiometabólico e, por isso, pode ser utilizado na atenção básica, considerando sempre que a escolha do ponto de corte deve ser baseada também na maneira pela qual a mensuração foi realizada.

No ELSA-Brasil, a CC foi mensurada no ponto médio entre a última costela e a crista ilíaca, logo o FCH-IDF é classificação adequada para este estudo. Além disso, para a realização de um rastreamento do risco cardiometabólico na saúde pública, é importante que um número maior de pessoas seja identificado por meio do indicador com menor ponto de corte. Entre os indivíduos com maior risco, ações de prevenção devem ser intensificadas e possivelmente realizados exames mais detalhados. Vale ressaltar que, apesar da facilidade para a mensuração da CC, é importante que haja um treinamento para a coleta dessa medida na equipe de saúde.

Os testes que compararam o FCH com indicadores do risco coronariano (escore de Framingham) e de resistência à insulina (índice HOMA-IR) apresentaram valores baixos e moderados, respectivamente, salvo os valores elevados de sensibilidade e especificidade do HOMA, sobretudo nos indivíduos do sexo masculino. Outros estudos encontraram a associação entre esses indicadores e FCH, mas foram utilizados métodos estatísticos diferentes para comparação deles, como, por exemplo, modelos de regressão ou comparação de prevalências 3,4,51,52. Os estudos supracitados não compararam o poder de predição de um indicador em relação ao outro, como nesta investigação. Se colocados nos modelos de regressão, o índice HOMA-IR estaria associado ao FCH em todos os modelos finais, com OR a variar de 2,4 a 4,5, e o escore de Framingham apenas nos modelos masculinos (dados não apresentados).

Por se tratar de uma coorte ocupacional que abrange a população brasileira de maneira mais ampla, considerando diferentes grupos etários, sexo e regiões do país, tais dados podem inferir prevalências de doenças crônicas ou fatores de risco para a população brasileira 9 . Porém, os resultados são provenientes da linha de base dessa coorte, e o corte transversal não permite fazer inferências quanto à relação de causa/efeito. Ademais, a falta de consenso quanto aos pontos de corte para definir a CC, e consequentemente o $\mathrm{FCH}$, tanto para a população mundial quanto para a brasileira, indica que mais estudos devem ser realizados sobre o tema, objetivando uma uniformização para cada população.

Neste artigo, o FCH foi associado à idade aumentada, consumo excessivo de álcool, ser exfumante, hipertenso, diabético, apresentar HDL baixo, não-HDL alto e PCR aumentado, independentemente do sexo ou critério de definição. A SM apresentou maior correlação com FCH entre os participantes de ambos os sexos. Os resultados do presente estudo sugerem que o FCH é uma boa alternativa para estimar o risco cardiometabólico e apoia a sua utilização como ferramenta de triagem para doenças cardiovasculares e diabetes em indivíduos aparentemente saudáveis, por conta de seu baixo custo, facilidade e viabilidade da medida, podendo ser usada na prática clínica e nos serviços públicos de saúde. 


\section{Colaboradores}

R. S. Freitas contribuiu com a concepção e projeto, análise e interpretação dos dados, redação do artigo e revisão crítica relevante do conteúdo intelectual. M. J. M. Fonseca, M. I. Schmidt e M. C. B. Molina revisaram e aprovaram a versão final a ser publicada. M. C. C. Almeida contribuiu com a redação do artigo, revisão crítica relevante do conteúdo intelectual e aprovação final da versão a ser publicada.

\section{Agradecimentos}

À equipe do ELSA-Brasil. Ao Ministério da Saúde, Ministério da Ciência e Tecnologia e CNPq pelo financiamento.

\section{Referências}

1. World Health Organization. World Health Statistics 2011. http://www.who.int/who sis/whostat/2011/en/ (acessado em 02/Dez/ 2015).

2. Lemieux I, Pascot A, Couillard C, Lamarche B, Tchernof A, Alméras N, et al. Hypertriglyceridemic waist: a marker of the atherogenic metabolic triad (hyperinsulinemia; hyperapolipoprotein B; small, dense LDL) in men? Circulation 2000; 102:179-84.

3. Blackburn P, Lemieux I, Alméras N, Bergeron J, Côté M, Tremblay A, et al. The hypertriglyceridemic waist phenotype versus the National Cholesterol Education Program-Adult Treatment Panel III and International Diabetes Federation clinical criteria to identify high-risk men with an altered cardiometabolic risk profile. Metabolism 2009; 58:1123-30.

4. Cabral Rocha AL, Pereira PF, Pessoa MC, Alfenas RCG, Segheto W, Silva DC, et al. Hypertriglyceridemic waist phenotype and cardiometabolic alterations in Brazilian adults. Nutr Hosp 2015; 32:1099-106.

5. Cabral NAL, Ribeiro VS, Franca AKTC, Salgado JVL, Santos AM, Salgado Filho N, et al. Hypertriglyceridemic waist and cardiometabolic risk in hypertensive women. Rev Assoc Med Bras 2012; 58:568-73.

6. Oliveira CCR, Roriz AKC, Eickemberg M, Medeiros JMB, Ramos LB. Hypertriglyceridemic waist phenotype: association with metabolic disorders and visceral fat in adults. Nutr Hosp 2014; 30:25-31.

7. Solati M, Ghanbarian A, Rahmani M, Sarbazi N, Allahverdian S, Azizi F. Cardiovascular risk factors in males with hypertriglycemic waist (Tehran Lipid and Glucose Study). Int J Obes Relat Metab Disord 2004; 28:706-9.

8. Esmaillzadeh A, Azadbakht L. Increased levels of inflammation among women with enlarged waist and elevated triglyceride concentrations. Ann Nutr Metab 2010; 57:77-84.

9. Schmidt MI, Duncan BB, Mill JG, Lotufo PA, Chor D, Barreto SM, et al. Cohort profile: Longitudinal Study of Adult Health (ELSABrasil). Int J Epidemiol 2014; 44:68-75.

10. Aquino EML, Barreto SM, Bensenor IM, Carvalho MS, Chor D, Duncan BB, et al. Brazilian Longitudinal Study of Adult Health (ELSABrasil): objectives and design. Am J Epidemiol 2012; 175:315-24.

11. Xavier HT, Izar MC, Faria Neto JR, Assad MH, Rocha VZ, Sposito AC, et al. V Brazilian Guidelines on Dyslipidemias and Prevention of Atherosclerosis. Arq Bras Cardiol 2013; 101(4 Suppl 1):1-20.

12. International Diabetes Federation. The IDF consensus worldwide definition of the metabolic syndrome. http://www.idf.org/webdata/ docs/IDF_Meta_def_final.pdf (acessado em 23/Set/2015).

13. Lean MEJ, Han TS, Morrison CE. Waist circumference as a measure for indicating need for weight management. BMJ 1995; 311:158-61. 
14. National Cholesterol Education Program. Executive summary of the Third Report of the National Cholesterol Education Program (NCEP) Expert Panel on Detection, Evaluation, and Treatment of High Blood Cholesterol in Adults (Adult Treatment Panel III). JAMA 2001; 285:2486-97.

15. Matsudo S, Araújo T, Marsudo V, Andrade D, Andrade E, Oliveira LC, et al. Questionário internacional de atividade física (IPAQ): estudo de validade e reprodutibilidade no Brasil. Rev Bras Ativ Fís Saúde 2001; 6:5-18.

16. Haskell WL, Lee I-M, Pate RR, Powell KE, Blair SN, Franklin BA, et al. Physical activity and public health: updated recommendation for adults from the American College of Sports Medicine and the American Heart Association. Med Sci Sports Exerc 2007; 39:1423-34.

17. Fuchs FD, Chambless LE, Whelton PK, Nieto FJ, Heiss G. Alcohol consumption and the incidence of hypertension: the Atherosclerosis Risk in Communities Study. Hypertension 2001; 37:1242-50.

18. National Center for Health Statistics, Centers for Disease Control and Prevention. National Health Interview Survey - Adult Tobacco Use Information. http://www.cdc.gov/nchs/nhis/ tobacco/tobacco_glossary.htm (acessado em 23/Nov/2015).

19. Levey AS, Stevens LA, Schmid CH, Zhang YL, Castro AF, Feldman HI, et al. A new equation to estimate glomerular filtration rate. Ann Intern Med 2009; 150:604-12.

20. Zanocco JA, Nishida SK, Passos MT, Pereira AR, Silva MS, Pereira AB, et al. Race adjustment for estimating glomerular filtration rate is not always necessary. Nephron Extra 2012; 2:293-302.

21. KDIGO 2012 clinical practice guideline for the evaluation and management of chronic kidney disease. Kidney Int Suppl 2013; 3:1-150.

22. Pearson TA, Mensah GA, Alexander RW, Anderson JL, Cannon 3rd RO, Criqui M, et al. Markers of inflammation and cardiovascular disease: application to clinical and public health practice: a statement for healthcare professionals from the Centers for Disease Control and Prevention and the American Heart Association. Circulation 2003; 107:499-511.

23. D'Agostino RB, Vasan RS, Pencina MJ, Wolf PA, Cobain M, Massaro JM, et al. General cardiovascular risk profile for use in primary care: the Framingham Heart Study. Circulation 2008; 117:743-53.

24. Girman CJ, Rhodes T, Mercuri M, Pyörälä K, Kjekshus J, Pedersen TR, et al. The metabolic syndrome and risk of major coronary events in the Scandinavian Simvastatin Survival Study (4S) and the Air Force/Texas Coronary Atherosclerosis Prevention Study (AFCAPS/TexCAPS). Am J Cardiol 2004; 93:136-41.

25. Matthews DR, Hosker JP, Rudenski AS, Naylor BA, Treacher DF, Turner RC. Homeostasis model assessment: insulin resistance and betacell function from fasting plasma glucose and insulin concentrations in man. Diabetologia $1985 ; 28: 412-9$.
26. Benseñor IM, Goulart AC, Molina MCB, de Miranda ÉJP, Santos IS, Lotufo PA. Thyrotropin levels, insulin resistance, and metabolic syndrome: a cross-sectional analysis in the Brazilian Longitudinal Study of Adult Health (ELSA-Brasil). Metab Syndr Relat Disord 2015; 13:362-9.

27. Baena CP, Lotufo PA, Fonseca MJ, Bensenor IJ. Abstract P148: Neck circumference as an independent contributor to cardio metabolic risk factors - ELSA BRASIL. Circulation 2015; 131 Suppl 1:AP148.

28. Garmendia ML, Lera L, Sánchez H, Uauy R, Albala C. Valores normativos de resistencia a la insulina mediante HOMA-IR en adultos mayores de Santiago de Chile. Rev Méd Chile 2009; 137:1409-16.

29. Conceição-Machado MEP, Silva LR, Santana MLP, Pinto EJ, Silva RCR, Moraes LTLP, et al. Hypertriglyceridemic waist phenotype: association with metabolic abnormalities in adolescents. J Pediatr 2013; 89:56-63.

30. Haack RL, Horta BL, Gigante DP, Barros FC, Oliveira I, Silveira VM. The hypertriglyceridemic waist phenotype in young adults from the Southern Region of Brazil. Cad Saúde Pública 2013; 29:999-1007.

31. Linares-Reyes E, Castillo-Minaya K, Ríos-Mino M, Huamán-Saavedra J. Study of correlation between diagnostic hypertriglyceridemic waist and metabolic syndrome in adults in Trujillo, Peru. Rev Peru Med Exp Salud Pública 2014; 31:254-60.

32. Chackrewarthy S, Gunasekera D, Pathmeswaren A, Wijekoon CN, Ranawaka UK, Kato N, et al. A comparison between revised NCEP ATP III and IDF definitions in diagnosing metabolic syndrome in an urban Sri Lankan population: The Ragama Health Study. ISRN Endocrinol 2013; 2013:320176.

33. Moon BS, Park H-J, Lee M-K, Jeon WS, Park SE, Park C-Y, et al. Increased association of coronary artery calcification in apparently healthy Korean adults with hypertriglyceridemic waist phenotype: the Kangbuk Samsung Health Study. Int J Cardiol 2015; 194:78-82.

34. Sociedade Brasileira de Cardiologia; Sociedade Brasileira de Hipertensão; Sociedade Brasileira de Nefrologia. VI Diretrizes Brasileiras de Hipertensão. Arq Bras Cardiol 2010; 95 (1 Suppl 1):1-51.

35. Sociedade Brasileira de Hipertensão; Sociedade Brasileira de Cardiologia; Sociedade Brasileira de Endocrinologia e Metabologia; Sociedade Brasileira de Diabetes; Associação Brasileira para Estudos da Obesidade. I Diretriz Brasileira de Diagnóstico e Tratamento da Síndrome Metabólica. Arq Bras Cardiol 2005; 84 Suppl 1:3-28.

36. World Health Organization. Obesity: preventing and managing the global epidemic. Geneva: World Health Organization; 2000. (WHO Technical Report Series, 894). 
37. Barbosa PJB, Lessa I, Almeida Filho N, Magalhães LBNC, Araújo J. Critério de obesidade central em população brasileira: impacto sobre a síndrome metabólica. Arq Bras Cardiol 2006; 87:407-14.

38. Matsushita Y, Tomita K, Yokoyama T, Mizoue T. Optimal waist circumference measurement site for assessing the metabolic syndrome. Diabetes Care 2009; 32:e70.

39. Carvalho CA, Fonseca PCA, Barbosa JB, Machado SP, dos Santos AM, da Silva AAM. The association between cardiovascular risk factors and anthropometric obesity indicators in university students in São Luís in the State of Maranhão, Brazil. Ciênc Saúde Coletiva 2015; 20:479-90.

40. Alavian S-M, Motlagh ME, Ardalan G, Motaghian M, Davarpanah AH, Kelishadi R. Hypertriglyceridemic waist phenotype and associated lifestyle factors in a national population of youths: CASPIAN Study. J Trop Pediatr 2008; 54:169-77.

41. Gomez-Huelgas R, Bernal-López MR, Villalobos A, Mancera-Romero J, Baca-Osorio AJ, Jansen S, et al. Hypertriglyceridemic waist: an alternative to the metabolic syndrome? Results of the IMAP Study (multidisciplinary intervention in primary care). Int J Obes 2011; 35:292-9.

42. Molica F, Morel S, Kwak BR, Rohner-Jeanrenaud F, Steffens S. Adipokines at the crossroad between obesity and cardiovascular disease. Thromb Haemost 2015; 113:553-66.

43. Kahn HS, Valdez R. Metabolic risks identified by the combination of enlarged waist and elevated triacylglycerol concentration. Am J Clin Nutr 2003; 78:928-34.

44. Rogowski O, Shapira I, Steinvil A, Berliner S. Low-grade inflammation in individuals with the hypertriglyceridemic waist phenotype: another feature of the atherogenic dysmetabolism. Metabolism 2009; 58:661-7.

45. Buchan DS, Boddy LM, Despres J-P, Grace FM, Sculthorpe N, Mahoney C, et al. Utility of the hypertriglyceridemic waist phenotype in the cardiometabolic risk assessment of youth stratified by body mass index. Pediatr Obes 2016; 11:292-8.
46. Saudny H, Cao Z, Egeland GM. Poor selfreported health and its association with biomarkers among Canadian Inuit. Int J Circumpolar Health 2012; 71:18589.

47. Després J-P, Lemieux I, Bergeron J, Pibarot P, Mathieu P, Larose E, et al. Abdominal obesity and the metabolic syndrome: contribution to global cardiometabolic risk. Arterioscler Thromb Vasc Biol 2008; 28:1039-49.

48. Millán Núñez-Cortés J, Mantilla Morató T, Toro R, Millán Pérez J, Mangas Rojas A. Sindrome metabólico en pacientes con fenotipo clínico de "cintura hipertrigliceridémica." Nutr Hosp 2015; 32:1145-52.

49. Carr DB, Utzschneider KM, Hull RL, Kodama $\mathrm{K}$, Retzlaff BM, Brunzell JD, et al. Intra-abdominal fat is a major determinant of the $\mathrm{Na}$ tional Cholesterol Education Program Adult Treatment Panel III criteria for the metabolic syndrome. Diabetes 2004; 53:2087-94.

50. Pereira PF, Faria FR, Faria ER, Hermsdorff HHM, Peluzio MCG, Franceschini SCC, et al. Anthropometric indices to identify metabolic syndrome and hypertriglyceridemic waist phenotype: a comparison between the three stages of adolescence. Rev Paul Pediatr 2015; 33:194-203

51. Espinoza ZM, Ruiz FN, Barrios E, Reigosa A, Leal HU, González JC. Cardiovascular risk profile and insulin resistance according body mass index, waist circumference and hypertriglyceridemic waist in adult subjects. Rev Méd Chile 2009; 137:1179-86.

52. Poirier J, Kubow S, Noël M, Dupont C, Egeland GM. The hypertriglyceridemic-waist phenotype is associated with the Framingham risk score and subclinical atherosclerosis in Canadian Cree. Nutr Metab Cardiovasc Dis 2015; 25:1050-5. 


\section{Abstract}

This study's objectives were to estimate the prevalence of hypertriglyceridemic waist (HTW) phenotype in participants in the Brazilian Longitudinal Study of Adult Health (ELSA-Brasil), identify associated risk factors, and compare with other cardiovascular and metabolic risk indicators. This was a cross-sectional study with baseline data from a cohort of public employees. HTW is defined as the simultaneous presence of increased waist circumference $(W C)(\geq 80 \mathrm{~cm}$ for women, $\geq 90 \mathrm{~cm}$ for men according to the International $\mathrm{Di}$ abetes Federation - IDF; and $\geq 88 \mathrm{~cm}$ for women, $\geq 102 \mathrm{~cm}$ for men according to the U.S. National Cholesterol Education Program - NCEP) and hypertriglyceridemia. Associations between independent variables and $H T W$ were tested with multivariate logistic regression models. HTW was also compared to other cardiovascular and metabolic risk indicators by means of correlation tests, kappa index, sensitivity, and specificity. After exclusions, 12,811 participants were analyzed. Prevalence of HTW ranged from $24.7 \%$ (IDF) to $13.3 \%$ (NCEP). $H T W$ was associated with age, excessive alcohol consumption, former smoking, low HDL, nonhigh HDL, and increased C-reactive protein, independently of gender or the criterion used to define HTW. HTW was associated with cardiovascular risk indicators, especially metabolic syndrome. The high prevalence of HTW and its association with cardiovascular risk indicators, especially metabolic syndrome, supports its use as a cardiometabolic risk screening tool in clinical practice.

Hypertriglyceridemic Waist; Metabolic Syndrome X; Abdominal Obesity; Risk Factors

\section{Resumen}

El objetivo de este estudio fue estimar la prevalencia del fenotipo cintura hipertrigliceridémica $(F C H)$, en participantes del Estudio Longitudinal de la Salud del Adulto (ELSA-Brasil), identificar factores de riesgo asociados, y compararlo con otros indicadores de riesgo cardiovascular $y$ metabólico. Se trata de un estudio transversal con datos de la línea de referencia de una cohorte de empleados públicos. El FCH se define por la presencia simultánea de circunferencia de la cintura (CC) aumentada ( $\geq 80 \mathrm{~cm}$ para mujeres, $\geq 90 \mathrm{~cm}$ para hombres de acuerdo con la Federación Internacional de Diabetes - IDF; $y \geq 88 \mathrm{~cm}$ para mujeres, $\geq 102 \mathrm{~cm}$ para hombres de acuerdo con el Programa National de Educación sobre el colesterol de los EE.UU. - NCEP) e hipertrigliceridemia. La asociación entre las variables independientes y FCH fue probada mediante modelos de regresión logística multivariada. El FCH se comparó también con otros indicadores de riesgo cardiovascular y metabólico, mediante pruebas de correlación, indice kappa, sensibilidad y especificidad. Tras las exclusiones, se analizaron a 12.811 participantes. La prevalencia del FCH varió de un 24,7\% (IDF) a un 13,3\% (NCEP). El FCH se asoció a tener una edad más avanzada, al consumo excesivo de alcohol, ser ex-fumador, presentar HDL bajo, no-HDL alto y PCR aumentado, independiente del sexo o criterio de definición. FCH se asoció a indicadores de riesgo cardiovascular, especialmente al sindrome metabólico. La elevada prevalencia de FHC y su asociación con indicadores de riesgo cardiovascular, especialmente con el síndrome metabólico, apoya su utilización como herramienta de clasificación de riesgo cardiometabólico en la práctica clínica.

Cintura Hipertrigliceridémica; Síndrome X Metabólico; Obesidad Abdominal; Factores de Riesgo
Recebido em 21/Abr/2017

Versão final reapresentada em 19/Jul/2017 Aprovado em 18/Ago/2017 